\title{
Research on Reverse Innovation of Performance Appraisal Based on the Methods of Factor Analysis
}

\author{
Wenping Zhao ${ }^{1}$, Mengyao $\mathrm{Li}^{2}$ \\ School of Economics and Management, Xidian University, Xi'an 710071, China
}

\begin{abstract}
Reverse innovation is a business and innovation model that is contrary to "globalization" and "localization". Reverse innovation has become a new trend of global development strategy of transnational enterprises. This article analyzing the trend of globalization and the emerging market conditions, quantified the innovation path of the enterprise through the method of factor analysis, and establish of the impact factors evaluation model about enterprise reverse innovation. The conclusions of this article can be used to adjust innovation strategy in the process of development, and ultimately achieve the strategic goal of the enterprise.
\end{abstract}

Keywords: reverse innovation; globalization; principle composition analysis; factor analysis

\section{Introduction}

The global growth strategy of transnational enterprises has gone through two remarkable stages: "globalization" and "localization". In the stage of "globalization", enterprises spread their innovation products all over the world through the global network of their own. In the stage of "Localization" , the enterprise study the market with branches all over the world, and perform targeted adjustments on it's innovation ideas and products which fit with local country or region market conditions to better suit the customer demands of the international markets.

(1) Along with the development of economic globalization, multinationals based in developed countries have adopted strategies combined with "globalization" and "localization" targeted at developing nations' market, which R\&D activities are conducted in their country's laboratory meeting developing countries demands with appropriate adjustments. This kind of innovation strategy has always been regarded by multinational company as the key to success, which lead to the situation that the spread of innovation all over the world mainly one-way flowed from developed countries to developing countries and even more fringes of the market. In this pattern, developing countries did just play a follower role in a project life cycle during later phases rather than the birthplace of technological innovation and sponsor.

(2) But with the changing environment and competitive landscape of global market, emerging markets has become the focus to gain sustainable global competitive advantage between transnational corporations. Recent years, western countries effective demand is insufficient due to the influence of economic crisis, while many emerging-market nations like China and India maintains a strong momentum of growth, arouse great attentions on transnational corporations. Companies from emerging countries take this opportunity to achieve rapid expansion and fight for the emerging-market consumer demand with transnational corporations. Under the stress of competition multinational companies in developed countries have use the emerging-market as the conducting place of $\mathrm{R} \& \mathrm{D}$ activity. The value position of emerging-market has gradually turns to the global innovation center from follower role in a project life cycle during later phases. More and more corporations have regard developing country as the hot topic in recent research, leverage it's global resource to develop products and services for local demands. Reverse innovation is a kind of innovative route and diffusion model which relevant techniques and products become mature and successful in the local market first, and also succeed when promoting in the opposite direction to developed countries market.

\section{Review of Research}

Both foreign and domestic scholars have studied reverse innovation at different levels. Govindarajan has did research at what types of innovation emerging-markets can rapid development rises, the diffusion path of reverse innovation and the competitive advantages of local and foreign companies. Shan pointed out the way that reverse innovation successfully extended to developed countries' product markets in his research, at the same time, Shan has conducted an empirical study on this kind of problems, implemented three typical product innovation of reverse innovation in Philips Electronics China Group. Zeschky found that the ability of frugal innovation is the key to reverse innovation through surveys of pharmaceutical and electronic multinationals. Laperche B and Lefebvre G believe that reverse innovation means to achieve local development, and turns out that the result of its innovation including materialized products and services are applicable worldwide. Xing Xiaoqiang and the others have defined the proprietary concept of reverse innovation and other emerging-market innovation in his report, describes the main realization of reverse innovation and building the preliminary framework of this field. Mr Rui have divided Chinese companies acceptance about overseas' management philosophy and software into three stages including learning stage, reformist stage and reverse innovation stage. He believes that more and more Chinese companies are beginning to summarized their management models and had a greater impact on foreign companies, become a new

Volume 6 Issue 12, December 2017 


\section{International Journal of Science and Research (IJSR) \\ ISSN (Online): 2319-7064}

Index Copernicus Value (2016): 79.57 | Impact Factor (2015): 6.391

standard and best practices. Liu Xiao defined and illustrates the concept of reverse innovation, reported the main features addressed related recommendations and conclude key success factors of reverse innovation. Liu Yu and $\mathrm{Ma}$ Wei has applied reverse innovation in practice, compared original products, indigenous innovation and methods of reverse innovation of General Electric Company during different periods and expand it's development process .

(1) This article analyzing the trend of globalization and the emerging market conditions, quantified the innovation path of the enterprise through the method of factor analysis, and establish of the impact factors evaluation model about enterprise reverse innovation. The conclusions of this article can be used to adjust innovation strategy in the process of development, have great significance in the field of reverse innovation.

(2) While the globalization of innovative activity was in its early years of development, information, acknowledge and product flow from particular developed countries to those developing countries. With the rise of emerging-market and the growth of emerging-markets firms, resource gift advantage and innovative cluster have offered a good condition for knowledge innovation activity of local emerging-market firms and the branch of the trans-national corporation.

(3) The appearance of emerging-market is not a new phenomenon, it is a new generation of emerging-market nations. Those countries are more numerous and has received increasing attention in developed countries than before, which wildly exists all over the world with strong complementarities. Higher development and returns 、 diversification 、 counter-cyclical、small market scale and immature investors are emerging-market features. The major subject of emerging-market are lower-income groups who tend to be more sensitive to the price and market demand flexibility is large, valuing the quality of product than other factors. Developed markets owns good infrastructure and regulations, which is exactly emerging-markets needs badly. Emerging countries like China exist long-term conflicts between economic development and natural environment which is imperative to find creative solutions. Innovation that based on developing market's demands and consumption characteristics cannot settle the emerging-market problems. Therefore, many transnational corporations decided to grasp emerging-market opportunity, design a new style according with actual conditions and implement specific strategies.

(4) After many years of knowledge accumulation in developed markets, it has formed its own unique innovation advantage. Silicon Valley has attracted innovative talents from all over the world, they have a lot of knowledge, a wide range of comprehensive abilities and creative spirits, which scientists and engineers occupies a relatively large proportion. Behind this, the accumulation of wealth make it possible to invest in research and development. Immature physical infrastructure in emerging-market is a temporary predicament, they tap their own potential and make good use of it, more technology talents back to their country and providing high-quality work force for local corporations. Emerging-market nation's government take effective measures to support technological innovations to improve synthetical strength. Emerging countries' proportions of spending on R\&D in GDP shows the increasing tendency year by year, government also offer preferential polices for innovative human resources and creative entrepreneurs. Innovative environment lays a good foundation on the occurrence for innovation. The difference between emerging market's cultural identity and economic factors with developed countries make the occurrence of reverse innovation a reality.

\section{Establish enterprise initial reverse innovation performance evaluation index system}

\section{(1) The selection of evaluating indicator}

Based on opening questionnaires, analyzing the literature and market research, a performance evaluation index system was developed about enterprise reverse innovation. Including 19 evaluation factors, as shown in Table 1.

Table 1: Enterprise initial reverse innovation performance evaluation index system

\begin{tabular}{|c|c|}
\hline Symbol Number & Evaluation Factor \\
\hline X1 & Company Assets \\
\hline X2 & Employee Motivation \\
\hline X3 & Enterprise's innovative ability \\
\hline X4 & Enterprise social relations network \\
\hline X5 & Government support \\
\hline X6 & Cocial infrastructure \\
\hline X7 & Cooperation with foreign enterprises \\
\hline X8 & Corporate culture \\
\hline X9 & Competition between enterprises \\
\hline X10 & Enterprise organizational structure \\
\hline X11 & Enterprise management mode \\
\hline X12 & Innovation society environment \\
\hline X13 & Talented person outputs quality \\
\hline X14 & Profits of the creation \\
\hline X15 & Enterprise developing strategy \\
\hline X16 &
\end{tabular}

\section{(2) Primitive data collection}

The data of above index system cannot be obtained from relevant statistics, the paper adopts the method of sampling questionnaire to collect data and gives weights to indexes. This paper makes a survey of business leaders, corporate employees, relevant academics and students to ensure the accuracy and reliability of testing figures. The indexes are assigned by 10 -point system to assess the importance of evaluation factors about enterprise reverse innovation performance evaluation index system, higher score represents higher importance. This investigation altogether provides questionnaire 100 , the actual recovery of 87 copies.

\section{Volume 6 Issue 12, December 2017}




\section{International Journal of Science and Research (IJSR) \\ ISSN (Online): 2319-7064}

Index Copernicus Value (2016): 79.57 | Impact Factor (2015): 6.391

(3) Selection of analysis methods

This literacy uses Factor analysis to analyze the performance of reverse innovation by choosing correlative factors. Factor analysis is a method of dimension reduction. It doses this by seeking underlying unobservable variables that are reflected in the observed variables, turned multi-index into several comprehensive indicators. The higher relationship between different evaluation relationship, eliminated information overlapping of the sample, and based on the original information provided by metadata obtain the weight coefficients in multiple evaluation indexes. The use of factor analysis for multi-index comprehensive evaluation has many advantages. First of all, during the process of transform original variables into principle factors, the method of factor analysis count the complex value of evaluation and produced the judgment weight which contains index components and information quantity at the same time. This kind of data process make sure the realistic relationship can be reflected which more objective and reliable than subjective judgments. In the second place, this method reduces the index selection workload and by the meantime maintain the most information. It can efficiently eliminate the effects of correlations between evaluation indexes, make the choose of assessing indexes more easier. Widely application of factor analysis in all kinds of comprehensive evaluation practice been realistic with the promotion and application of statistical analysis software like SAS, SPSS. Having evaluation indexes and factors as much as possible merged together, the principle factors of enterprises competition relations can be extracted from the raw data by condensing multiple indexes into several that represents mainly information and conducting correlation and representation analysis. With all the operations above, the corporation's competition relations system was established.

\section{Structure the performance evaluation system of reverse innovation}

\section{(1) Confirm principle factors}

Base on original data, factor analysis is carried out with SPSS software, reducing the original variances from 19 to 3. The first step in analyzing is to put in all the data, calculating the KMO test of sphericity and Sig. score base on those data. The results shows that the KMO number was 0.93 and Sig. was 0.000 , both of them indicates that scale structure is effective and suitable for factor analysis.

The second step is arrange all principle factors in descending order of variances, count the accumulative variance contribution of principal components and capture few factors as principal factors which indicates more information. Component Matrix as shown in FIG.2. The characteristic value, variance contribution both before and after rotation of principal factors as shown in FIF.3

As shown in FIG.2, the first three factors' accumulative variance that been extracted has reached $81.829 \%$, it represents and reflects the core values of the big part of the raw data. Therefore 19 indexes in original system can be divided into three principle factors which can reflect all of sample information sufficiently.

Table 2: The initial factor load matrix

\begin{tabular}{|c|c|c|c|}
\hline & \multicolumn{3}{|c|}{ 成分 } \\
\hline & 1 & 2 & 3 \\
\hline Company Assets & -.099 & .363 & -.480 \\
\hline Employee Motivation & -.044 & .130 & .184 \\
\hline Enterprise's innovative ability & -.499 & -.099 & .459 \\
\hline Enterprise social relations network & -.464 & -.077 & .163 \\
\hline Government support & .382 & -.072 & .482 \\
\hline Comprehensive quality of human resources & .241 & .295 & -.096 \\
\hline Social infrastructure & .059 & -.676 & -.132 \\
\hline Cooperation with foreign enterprises & .256 & -.004 & -.247 \\
\hline Knowledge absorptive capacity & .426 & .184 & .336 \\
\hline Corporate culture & .107 & .062 & .039 \\
\hline Enterprise knowledge transfer process & .465 & -.557 & .006 \\
\hline Competition between enterprises & .663 & .084 & .252 \\
\hline Enterprise organizational structure & .397 & .490 & .342 \\
\hline Enterprise management mode & -.264 & .195 & .533 \\
\hline Innovation society environment & .417 & .436 & -.348 \\
\hline Talented person outputs quality & .427 & -.379 & -.136 \\
\hline Innovative enterprises' performance evaluation & .059 & -.154 & .002 \\
\hline Profits of the creation & .436 & -.230 & .141 \\
\hline Enterprise developing strategy & -.069 & .086 & -.169 \\
\hline
\end{tabular}

Extracted method: principal component

a. Already extracted 3 principal components

Table 3: Explanation of the variance with loading

\begin{tabular}{|c|c|c|c|c|c|c|c|c|c|c|}
\hline & \multicolumn{3}{|c|}{ 初始特征值 } & \multicolumn{3}{c|}{ 提取平方和载入 } & \multicolumn{3}{c|}{ 旋转平方和载入 } \\
\hline 成份 & 合计 & 方差的\% & 累积\% & 合计 & 方差的\% & 累积\% & 合计 & 方差的\% & 累积\% \\
\hline 1 & 9.650 & 32.952 & 32.952 & 9.650 & 32.952 & 32.952 & 6.469 & 29.803 & 30.803 \\
\hline 2 & 2.273 & 25.825 & 68.777 & 2.273 & 25.825 & 68.777 & 4.115 & 27.593 & 57.397 \\
\hline 3 & 1.271 & 23.052 & 81.829 & 1.271 & 23.052 & 81.829 & 2.611 & 24.432 & 81.829 \\
\hline 4 & 0.924 & 3.401 & 82.230 & & & & & & \\
\hline 5 & 0.805 & 1.832 & 87.061 & & & & & & \\
\hline 6 & 0.693 & 1.302 & 88.364 & & & & & & \\
\hline 7 & 0.664 & 1.261 & 89.625 & & & & & & \\
\hline 8 & 0.641 & 1.252 & 90.876 & & & & & & \\
\hline 9 & 0.535 & 0.948 & 91.924 & & & & & & \\
\hline 10 & 0.473 & 0.853 & 92.677 & & & & & & \\
\hline 11 & 0.462 & 0.799 & 93.476 & & & & & & \\
\hline 12 & 0.426 & 0.729 & 94.205 & & & & & & \\
\hline 13 & 0.387 & 0.742 & 94.947 & & & & & & \\
\hline 14 & 0.337 & 0.603 & 95.549 & & & & & & \\
\hline
\end{tabular}

Volume 6 Issue 12, December 2017 


\section{International Journal of Science and Research (IJSR) \\ ISSN (Online): 2319-7064}

Index Copernicus Value (2016): 79.57 | Impact Factor (2015): 6.391

\begin{tabular}{|l|l|l|l|l|l|l|l|l|l|}
\hline 15 & 0.294 & 0.600 & 96.149 & & & & & & \\
\hline 16 & 0.281 & 0.538 & 96.687 & & & & & & \\
\hline 17 & 0.259 & 0.534 & 97.221 & & & & & & \\
\hline 18 & 0.195 & 0.530 & 97.951 & & & & & & \\
\hline 19 & 0.168 & 0.799 & 98.750 & & & & & & \\
\hline
\end{tabular}

\section{(2) Calculate the component matrix}

The factor load matrix is the coefficients of each primitive variables' expression which indicates the level of extracted common factor effects to primitive variance. As shown in the chart each index in the initial factor load matrix don't have obviously concentrated load in every principle factors, to get better principle factors needs a rotation matrix that calculated from the method of varimax rotation, the rotation component matrix as shown in FIG.4. According to the basically rule of factor analysis the load value of factor in one component twice as uch as others or greater than 0.4 , this component could be extracted for representation. After conducting the varimax rotation, all of variances loaded in one single principal component that shows great discriminant effectiveness and each variances corresponding to one component.

Table 4: Rotation matrix

\begin{tabular}{|c|c|c|c|}
\hline & \multicolumn{3}{|c|}{ 成分 } \\
\hline Enterprise organizational structure & 1 & 2 & 3 \\
\hline Comprehensive quality of human resources & 159 & .320 & .163 \\
\hline Enterprise developing strategy & .121 & .111 & .161 \\
\hline Enterprise knowledge transfer process & .330 & .413 & .303 \\
\hline Enterprise's innovative ability & .585 & -.139 & .147 \\
\hline Enterprise management mode & .222 & .074 & .687 \\
\hline Company Assets & .653 & .250 & .145 \\
\hline Knowledge absorptive capacity & .220 & .467 & .353 \\
\hline Employee Motivation & .608 & .173 & .341 \\
\hline Government support & .149 & .110 & .082 \\
\hline Social infrastructure & .051 & .662 & .166 \\
\hline Talented person outputs quality & 132 & .216 & .529 \\
\hline Corporate culture & .227 & .423 & .131 \\
\hline Competition between enterprises & .008 & .328 & .137 \\
\hline Innovation society environment & .180 & .115 & .657 \\
\hline Enterprise social relations network & .565 & .084 & -.049 \\
\hline Cooperation with foreign enterprises & .136 & .657 & -.188 \\
\hline Profits of the creation & .013 & .022 & .163 \\
\hline Innovative enterprises' performance evaluation & .357 & .078 & .359 \\
\hline
\end{tabular}

Extracted method: principal component

Rotation method: Varimax rotation with Kaiser standard

a. Rotation turned to convergence after 9 iterations

\section{(3) Constructing comprehensive evaluation system}

For quantification purposes, require data processing to survey samples. There are three steps to constructing the performance evaluation system of reverse innovation, the first step is computed each components scores based on data result sets. The second step is calculate the proportion of each principal components' accumulative variance among total accumulative variance. The last step is count the comprehensive evaluation values of corporation's competition relationship from the weighted average of data concluded form step two.

The value formulas of principle components:

$$
F_{i}=a_{i 1} X_{1}+a_{i 2} X_{2}+\cdots+a_{i 19} X_{19}
$$

$F_{i}$ is the score of number i-th principal factors, $a_{i 1}$, $a_{i 2}, \ldots a_{i 19}$ represents that the load of every index in number $i$-th, the score of each principal component can be calculated from above formulas.

The performance evaluation model of enterprise reverse innovation is:

$\mathrm{F}=0.402 F_{1}+0.316 F_{2}+0.282 F_{3}$

F represents the comprehensive score of the performance evaluation model of enterprise reverse innovation in the model showed above, the coefficient of $F_{1}, F_{2}, F_{3}$ are calculated from the weighted average of data, which weights come from the proportion of each principal components' accumulative variance among total accumulative variance. The value of $F_{1}, F_{2}, F_{3}$ are comes from the formula of principal component score and $\mathrm{F}$ represents the performance degree of corporation's reverse innovation.

\section{Conclusion}

\section{(1) Exploring factor analysis}

The results of factor analysis shows that the variance of the first principle factor reached to $32.952 \%$, the second is $25.825 \%$ and the accumulative variance of the third up to $81.829 \%$. It demonstrates that these three factors are kernel and basis of performance of enterprise reverse innovation. They have distinct proportions but didn't appear to be much different which illustrate that they almost share the same significance and make it each other possible, all these factors have come together play a decisive role in performance of reverse innovation in corporation.

\section{(2) Enterprise's reverse innovation performance assessment system}

According to the result of factor analysis three principal factors have been extracted, named three of them based on characteristic of different factors which are enterprise's innovation capability, government support for entrepreneur and social creative environment, explanations as follows.

Table 5: Enterprise's reverse innovation performance assessment system

\begin{tabular}{|c|c|}
\hline $\begin{array}{c}\text { First class } \\
\text { indicator }\end{array}$ & Evaluation factors \\
\hline \multirow{4}{*}{$\begin{array}{c}\text { Enterprise's } \\
\text { innovative } \\
\text { ability }\end{array}$} & Enterprise organizational structure \\
\cline { 2 - 2 } & Comprehensive quality of human resources \\
\cline { 2 - 2 } & Enterprise developing strategy \\
\cline { 2 - 2 } & Enterprise knowledge transfer process \\
\cline { 2 - 2 } & Enterprise's innovative ability \\
\cline { 2 - 2 } & Comprise management mode \\
\hline
\end{tabular}

\section{Volume 6 Issue 12, December 2017} www.ijsr.net 


\section{International Journal of Science and Research (IJSR) \\ ISSN (Online): 2319-7064}

Index Copernicus Value (2016): 79.57 | Impact Factor (2015): 6.391

\begin{tabular}{|c|c|}
\hline & Knowledge absorptive capacity \\
\hline & Employee Motivation \\
\hline \multirow{4}{*}{$\begin{array}{c}\text { Government } \\
\text { support }\end{array}$} & Government support \\
\hline & Social infrastructure \\
\hline & Talented person outputs quality \\
\hline & Corporate culture \\
\hline \multirow{6}{*}{$\begin{array}{c}\text { Innovation } \\
\text { society } \\
\text { environment }\end{array}$} & Competition between enterprises \\
\hline & Innovation society environment \\
\hline & Enterprise social relations network \\
\hline & Cooperation with foreign enterprises \\
\hline & Profits of the creation \\
\hline & Innovative enterprises' performance \\
\hline
\end{tabular}

Enterprise's innovation capability means the technological innovation and technological development of the enterprises, it is the key factor to corporation's performance of reverse innovation. This first class indicator includes enterprise organizational structure, comprehensive quality of human resources, enterprise developing strategy, enterprise knowledge transfer process, enterprise's innovative ability, enterprise management mode, company assets, knowledge absorptive capacity and employee motivation.

Government support for entrepreneur means that sufficient government policy support and spending to enterprises which contains government support, social infrastructure, talented person outputs quality and corporate culture.

Social creative environment is the company's operating market innovation atmosphere, the level of social innovation enthusiasm will have significant impact on the performance of enterprise innovation. This first-level indexes including competition between enterprises, innovation society environment, enterprise social relations network, cooperation with foreign enterprises, profits of the creation and innovative enterprises' performance evaluation.

(3) The application of enterprise's reverse innovation performance evaluation system

The system of enterprise's reverse innovation performance assessment provides tools for corporations to judge the level of reverse innovation performance. Enterprises could calculate degree of performance of reverse innovation rapidly and accurate based on above formulas, qualified creative problems so that corporations can adjust strategies and improve the efficiency of the economy. Reverse innovation that connected to different layers of market around the world is different from the other, which is a potent combination of localization and globalization, it created a new innovation model and creative diffusion path. Enterprises need to enhance the ability of chance recognition about reverse innovation and conducting deep research in it's impacting mechanism to build up same economic strength with established multinational enterprise, leverage the reverse innovation adjustment function effectively and gain share upon the more and more competitive and prosperous market. The application of enterprise's reverse innovation performance evaluation system helps company to capture market opportunity in time in the condition of grasped occurrence and effect mechanism, create more social economic effects and achieve company's strategy targets.

\section{Research Innovation and Prospects}

In this paper, a large number of related literature on reverse innovation has been reviewed, on the basis of listen to the advice of experienced experts in performance evaluation system of reverse innovation a questionnaire survey was conducted among relevant company staffs and professional scholars. All those primitive work have identified factors that effect enterprise's reverse innovation, principal components have been extracted by factor analysis, and therefore the performance evaluation system of enterprise's reverse innovation is starting to take shape.

However the selection of indexes still needs to be demonstrated and consummated. This paper based on a questionnaire survey by factor analysis, data information and respondents coverage is limited which needs more broader and deeper, also professional research and test. Hope this paper could bring some social value and economic value for interested scholars and relevant companies. The relationship between reverse innovation and normal, innovation and benefits requires further study, integrated traditional innovation performance theory and reverse innovation by performance theory to build a research framework includes resource reliance, government support and creative environment. On thebasis of continuously developing and expanding the present research methods, masters the effective way to conducting innovation to bring more economic benefit.

Therefore, for further the directing functions to management practice scholars need to fill the gaps and make in-depth and rigorous studies in fields of reverse innovation, this is the direction of our further research.

\section{References}

[1] Prahalad C K. Bottom of the pyramid as a source of break- through innovations. Journal of Product Innovation Management, VOL.29, NO.1, PP. 6, 2012.

[2] Xing Xiaoqiang, Zhou Jianghua, Tong Yunhuan. A review and policy implication on inclusive innovation. Science Research Management, VOL,36 NO. 9, PP, 11 $18,2015$.

[3] Zedtwitz M, Corsi S, Soberg P V, et al. A typology of reverse innovation. Journal of Product Innovation Management, VOL.32, NO.1, PP.12 - 28, 2014.

[4] Zheng Gang, Guo Yanting, Luo Guangxiong, et al. Techno- logical catch - up, dynamic capabilities and innovation capa-bilities: A case study of CIMC Tank Container. Science Research Management, VOL.37, NO.3, PP.31 - 41,2016.

[5] Dong Jielin, Chen Juan. Seamless open innovation: The prod- uct innovation model of Xiaomi in the Internet ecosystem. Science Research Management, VOL.35, NO.12, PP.76 - 84, 2014.

[6] Yip G, McKern B. Innovation in emerging markets: The case of China. International Journal of Emer- ging 


\section{International Journal of Science and Research (IJSR) \\ ISSN (Online): 2319-7064}

Index Copernicus Value (2016): 79.57 | Impact Factor (2015): 6.391

Markets, VOL.9, NO.1, PP.2-10, 2014.

[7] Vernon R. International investment and international trade in the product cycle. The Quarterly Journal of Economics, VOL.80, NO.2, PP.190-207, 1966.

[8] Reverse Innovation: An Interview with Vijay Govindarajan. Euchner,Jim. Research Technology Management. NO.6, 2012.

[9] Fortune at the bottom of the innovation pyramid: The strategic logic of incremental innovations[J] . Rajan Varadarajan. Business Horizons . 2008 (1)

Volume 6 Issue 12, December 2017

www.ijsr.net

Licensed Under Creative Commons Attribution CC BY 